\title{
A Correlational Approach on the Influence of Stress Level on the Job Performance of Employees in a Private Hospital
}

\author{
${ }^{1}$ Ryan $\mathrm{O}$ Maramba, ${ }^{2}$ Jordan H Llego
}

\section{ABSTRACT}

Aim: This study assesses the level of stress and its relationship to the job performance of the employees in a private hospital.

Materials and methods: This study used a descriptive-correlational design using a questionnaire. The total enumeration was used in this study to represent the population adequately with 295 respondents. To analyze the data frequency, percentage, mean, and Pearson-r were utilized.

Results: Results include: (43.70\%) are 25-34 years old; $(63.40 \%)$ are females; $(52.20 \%)$ of them is rendering their service less than five years; (31.20\%) are earning 9060 to 10059 pesos; (32.20\%) are in the nursing department. The stress level of the respondents had a mean score of 2.31. The overall job performance of the employees shows a mean score of 3.43 . Also, Pearson- $r$ revealed a score of $(r=-0.17, n=295, p=0.01)$.

Conclusion: The researchers conclude that: the hospital employees in a secondary hospital in Urdaneta City are young adults, that is female dominated and are relative neophytes who are making a decent amount of money, who are nurses. Hospital employees are experiencing minimal stress. The employees are a high-performing human resource. The stress level of the employees has a minimal damaging connection with their overall job performance.

Clinical significance: The results of this study will be a guide for the plans and activities in stress control, and enhancement of employees' job performance. Moreover, the results of this study will increase the employees' awareness about the stress they are experiencing, their job performance level, and how stress influences their job performance. The findings of this study will also give patients information about the quality of service the employees provide to them.

Keywords: Correlational study, Job performance, Private hospital, Stress level, Urdaneta city.

How to cite this article: Maramba RO, Llego JH. A Correlational Approach on the Influence of Stress Level on the Job Performance of Employees in a Private Hospital. Int J Res Foundation Hosp Healthc Adm 2018;6(2):68-73.

Source of support: Nil

Conflict of interest: None

\footnotetext{
${ }^{1}$ Human Resource Manager, ${ }^{2}$ Assistant Professor

${ }^{1}$ Human Resource Department, Urdaneta Sacred Heart Hospital, Urdaneta City, Pangasinan, Philippines

${ }^{2}$ College of Nursing, University of Hail, Kingdom of Saudi Arabia

Corresponding Author: Jordan H Llego, Assistant Professor College of Nursing, University of Hail, Kingdom of Saudi Arabia, e-mail: llegojordan@gmail.com
}

\section{INTRODUCTION}

Human capital is the greatest asset of an organization. Job performance of employees will dictate the success of an organization. Therefore it is the thrust of an organization to maintain, enhance and uplift the performance of its employees. There are several factors that could affect the performance of employees, and one of them is stress.

The American Institute of Stress, state that stress is a highly subjective phenomenon that it defies definition. However, Hans Selye coined the first definition of stress in 1936 which he defined as "the non-specific response of the body to any demand for change." Moreover, stress is a circumstance of the environment in which powers from the inside or outside world affects the individual, either one's emotional or physical well-being, or both. ${ }^{1}$

Stress has many effects on a person it can affect the nervous system, musculoskeletal system, respiratory system, cardiovascular system, endocrine system, and gastrointestinal system. Furthermore, stress is linked to depression, anxiety, heart attacks, stroke, hypertension, immune system disturbances that increase susceptibility to infections, ${ }^{2}$ this effect of stress could affect any individual. If a worker or an employee is undergoing stress, it might affect their performance in their job.

According to Tan, stress can overthrow a person that may result in depression, resorting to destructive behavior, toward self and others. ${ }^{3}$ The author also claims that Filipinos do not say they are stressed when facing one. Instead, it is manifested by producing illnesses, both physical and mental, both fleeting and serious, lifethreatening ones. The cause of stress or "stressors" is not universal; the author claims that stressors vary differently from sensory stressors such as noise, and many other sources like work and family.

Moreover, according to Hamlett, the adverse effects of stress include poor time management, strained relationships, and lack of focus. ${ }^{4}$ At the organizational level, the poor performance, unmet deadlines, and expectations will affect the organizations overall performance. Stress could also lead to high turnovers, sacrificing human capital. Stress also leads to health problems like hypertension, ulcers, gastric upset, sexual problems, appetite changes, and weight changes. ${ }^{4,5}$ 
The definition of job performance at first glance is very straightforward, according to The Wharton School, the University of Pennsylvania, job performance is a person's performance in a job, or how a worker performs his job. ${ }^{6}$ Job Performance is an essential factor in every business or service. Business success relies on its employees because they are considered the most significant assets. An intense level of job performance is a suggestion that the human resources department is doing their job. Moreover, excellent job performance boosts the business's reputation and is essential not just to consumers and shareholders, but also to possible clients and possible new hires, beyond the organization. ${ }^{7}$ On the other hand, if employees are poor performing the business will be jeopardized.

According to Ankari, depending on the level of stress, it can be helpful or harmful. The author claims that as stress gradually increases the job performance also increases because stress aids a worker to collect and utilize the available resource in the completion of his job. ${ }^{8}$ The author further claims, that high-stress level is destructive to one's job performance, this finding is supported by the claim of sincero that as stress becomes unmanageable, a person may experience a gradual to a drastic decrease in job performance. ${ }^{9}$ Thus, there will be a decline in enthusiasm and productivity.

Healthcare workers are essential in the overall health of people in the community and play an essential role in the sustenance of a healthy community. It is the role of the Department of Human Resource to keep the human capital healthy so that they will be productive and proactive. With all these premises in mind, the researcher wants to assess the level of stress of the healthcare workers, their job performance, and the relationship between the two variables. This study will also be a baseline for the private hospital in developing a program to lessen the stress being experienced by the healthcare workers.

This study assesses the level of stress and its relationship to the job performance of the respondents in a private hospital. Specifically, it answers the following problems:

- What is the profile of the respondents regarding:

- Age;

- Sex;

- Length of service;

- Monthly income; and

- Assigned department?

- What is the stress level of the respondents?

- What is the level of the job performance of the respondents?

- Is there a significant relationship between the stress level and job performance of the respondents?
The following hypothesis guided this study and was tested at the alpha level of 0.5. There is no significant relationship between the stress level and job performance of the respondents.

With the findings of this study, it will be beneficial to the following groups and people: to the Hospital Administrators. The results of this study will be a guide for the plans and activities in stress control, and enhancement of employees' job performance; to the Department of Human Resource. The results of this study will serve as baseline data for the department, and will also be a mirror of their performance in keeping their employees' wellness and productivity; to the Hospital Employees. The results of this study will increase the employees' awareness about the stress they are experiencing, their job performance level, and how stress influences their job performance; to the patients. The results of this study will give the patients a concrete evaluation of the job performance of the employees. The findings of this study will also give them information about the quality of service the employees provide to them, and to future researchers. The findings of this study could be a future reference for researchers who are of interest in the same research endeavor.

\section{MATERIALS AND METHODS}

\section{Research Design}

This study used to use a descriptive-correlational design. A descriptive study design aims to examine a sample at one specific point in time without making any inferences or causation. The present study describes the variables being examined and a correlational study aims to look at the relationship between two variables..$^{10}$ The current study describes the demographic profile, stress level and job performance of the respondents, and examines the relationship between stress level and job performance without inferring causation. Thus, these research designs apply to this study.

\section{Respondents of the Study and Sampling Scheme}

The locale of the study will be at a secondary private hospital located at Urdaneta City, Pangasinan. Specifically, the study will focus on first-line employees and their respective department head. The total enumeration was used in this study to represent the population adequately ${ }^{11}$ with 295 respondents.

The respondents of this study will be first-line employees of the secondary private hospital in Urdaneta City, regardless of age and sex and department being assigned, they will assess their stress level. Meanwhile, 
the department heads will be the one to assess the job performance of the first-line employees directly supervised by them.

\section{Ethical Consideration}

Before the actual data collection, one of the researchers passed the research proposal to the research review board of the secondary hospital.

There is a letter of consent/implied consent that is attached to the questionnaire that will be answered by the respondents, indicating the purpose of the study, the time needed to finish answering the questionnaire, the pros, and cons of the study. In the consent form of the employees, it will also be indicated that their department heads will evaluate them. Further, the respondents have the right to refuse not to participate in the study without any coercion.

All data is treated with the highest respect, confidentiality, and anonymity.

\section{Data Gathering Instrument}

The primary data gathering tool for the study is a questionnaire. There are two sets of questionnaires the first one is the questionnaire to be answered by the first-line employee, and the department heads answer the second one.

The first questionnaire is composed of two parts. Part I (one) covers the demographic profile of the respondents, this includes the respondents' age, sex, length of service, monthly income, and the current department assigned. Part II (two) was adopted and modified from the perceived stress scale, this was used because of it is already tested to measure the stress level of an individual, and it is widely used and already available, the instrument yielded a 0.72 Cronbach's Alpha coefficient, this means that has the right internal consistency and reliability. ${ }^{12}$ Part II is composed of 10 items and is answerable by the following scale "1-never," "2-sometimes," "3-fairly often," "4-very often." Moreover, items 4, 5, 7, and eight will be treated with reverse scoring.

The second set of the questionnaire will be adapted from the performance evaluation tool of the hospital. The questionnaire is scaled as follows "1-unsatisfactory," "2-needs improvement," "3-satisfactory," "4-very good."

\section{Collection of Data}

After securing all the approval needed by the researcher, the researcher personally administered the questionnaire; the researcher stays with the respondents during the data gathering so that if there are any questions, the researcher is available for clarifications.
Data collection and retrieval had occurred in July 2018.

\section{Treatment of Data}

The data that was collected in this study were analyzed using the Statistical Package for Social Sciences (SPSS) version 22 .

To answer sub-problems number one, frequency and percentage is used because the data in this part are nominal and categorical.

To answer sub-problem number two, mean is utilized. For the type of data that will be collected here is continuous, and is described as follows:

\begin{tabular}{llll}
\hline Score & $\begin{array}{l}\text { Statistical } \\
\text { range }\end{array}$ & $\begin{array}{l}\text { Descriptive } \\
\text { equivalent }\end{array}$ & $\begin{array}{l}\text { Transmuted } \\
\text { rating }\end{array}$ \\
\hline 4 & $3.25-4.00$ & Very often & High stress \\
3 & $2.50-3.24$ & Fairly often & Moderate stress \\
2 & $1.75-2.49$ & Sometimes & Slight stress \\
1 & $1.00-1.74$ & Never & No stress \\
\hline
\end{tabular}

To answer sub-problem number three, mean is used. For the type of data that was collected here is continuous data and is described as follows:

\begin{tabular}{lll}
\hline Score & Statistical range & Descriptive equivalent \\
\hline 4 & $3.25-4.00$ & Very good \\
3 & $2.50-3.24$ & Satisfactory \\
2 & $1.75-2.49$ & Needs improvement \\
1 & $1.00-1.74$ & Unsatisfactory \\
\hline
\end{tabular}

To answer sub-problem number four, Pearson-r is utilized, because the data that will be analyzed are both continuous data.

\section{RESULTS}

Table 1 displays the distribution of the respondents regarding their age, sex, length of service, monthly income, and the department assigned. It can be seen that many (43.70\%) are 25 to 34 years old; some $(33.60 \%)$ are $35-54 \%$; very few (18.60\%), and (4.10\%) are below 25 years old and 55 years old above. Regarding the sex of the respondents, it can be gleaned that the vast majority $(63.40 \%)$ are females, and some $(36.60 \%)$ are males. In terms of their length of service it shows that the majority $(52.20 \%)$ of them is rendering their service under five years; few $(24.40 \%)$ of them are in the hospital for 6-10 years, and very few (13.20\%), (10.20\%) are serving in the hospital for 11 to 15 years and 16 years and above respectively. Regarding their monthly income, some (31.20\%), (27.80\%) are earning 9060 to 10059 pesos, and 11060 to 12059 pesos, and very few (18.30\%), (14.90\%) and (7.80) are earning 13060 pesos and above, 8060 to 9059 pesos and 12060 to 13059 pesos respectively. In terms of the department assignment by the employees, it shows that some (32.20\%) and (23.70\%) are in the nursing and 
Table 1: Distribution of the respondents according to age, sex, length of service, monthly income, and department assigned $\mathrm{N}=295$

\begin{tabular}{lll}
\hline Variable & Frequency & Percentage (\%) \\
\hline Age & 55 & 18.60 \\
Below 25 years old & 129 & 43.70 \\
25-34 years old & 99 & 33.60 \\
35-54 years old & 12 & 4.10 \\
55 years old and above & & \\
Sex & 108 & 36.60 \\
Male & 187 & 63.40 \\
Female & & \\
Length of service & 154 & 52.20 \\
Below five years & 72 & 24.40 \\
6-10 years & 39 & 13.20 \\
11-15 years & 30 & 10.20 \\
16 years and above & & \\
Monthly Income & 44 & 14.90 \\
8060-9059 Pesos & 82 & 27.80 \\
9060-0059 Pesos & 92 & 31.20 \\
11060-12059 Pesos & 23 & 7.80 \\
12060-13059 Pesos & 54 & 18.30 \\
13060 and above & & \\
Department assigned & 7 & 2.40 \\
Medical & 16 & 5.40 \\
Dietary & 70 & 23.70 \\
General support & 95 & 32.20 \\
Nursing & 60 & 20.30 \\
Ancillary & 47 & 15.90 \\
Administrative & & \\
\hline
\end{tabular}

general support department respectively, few $(20.30 \%)$, and $(15.90 \%)$ are assigned in the ancillary and administrative department respectively, and very few $(5.40 \%)$, and $(2.40 \%)$ are assigned in the dietary and medical services.

Table 2 depicts the stress level of the respondents; it can be seen that the mean score revealed a score of 2.31.

Table 3 shows the job performance of the employees with a mean score of 3.43 .

Table 4 summarizes the relationship between the stress level and job performance level of the hospital employee. In this test of a relationship, the researcher coded the stress level and job performance in an increasing manner. To interpret the table, it must be made clear that the null hypothesis $\left(\mathrm{H}_{0}\right)$ was tested at alpha 0.05 . At this significance level in SPSS, the $\mathrm{H}_{0}$ is to be rejected if and only if the p-value is equal to or less than 0.05 .

Table 3: The Job performance level of the respondents $N=295$

\begin{tabular}{lll}
\hline & Weighted mean & Interpretation \\
\cline { 2 - 2 } Work performance & 3.43 & \\
\hline Legend & & \\
\hline & & Descriptive \\
Statistical Range & Equivalent & \\
\hline $1.00-1.74$ & Unsatisfactory & \\
$1.75-2.49$ & Needs Improvement & \\
$2.50-3.24$ & Satisfactory & \\
$3.25-4.00$ & Very Good & \\
\hline
\end{tabular}

Table 2: Stress level of the respondents $N=295$

\begin{tabular}{lll}
\hline \multirow{2}{*}{ Stress Level } & Weighted mean & Transmuted rating \\
\cline { 2 - 2 } Legend & 2.31 & \multicolumn{1}{c}{ slightly stress } \\
\hline Statistical Range & $\begin{array}{l}\text { Transmuted } \\
\end{array}$ & Rating \\
\hline $3.25-4.00$ & High Stress \\
$2.50-3.24$ & Moderate Stress \\
$1.75-2.49$ & Slight Stress \\
$1.00-1.74$ & No Stress \\
\hline
\end{tabular}

Pearson-r revealed $(r=-0.17, n=295, p=0.01)$, the null hypothesis is rejected; there is a significant weak negative relationship between the stress level of the employees and their work performance.

\section{DISCUSSION}

The data showed in Table 1 that the vast majority of the hospital workers are young adults, and this is parallel to the data of the Labor Force Survey of the Philippine Statistic Authority wherein a vast majority $(67.90 \%)$ of workers in the Philippines are young adults with ages 15 - 45 years old..$^{13}$ In terms sex, the number infers that female employees dominate the hospital, this is opposed to the data of Philippine Statistics wherein, males are in a higher number than females with a 2:1 ratio. ${ }^{13}$ The result in the number of years in the length of service infers that a significant majority of the previous employees have sought another career and left the hospital, this is congruent to the finding of Rigby, who said that the average year spent of an employee is 4.6 years. ${ }^{14}$ In terms of monthly income, the data show that the vast majority of the employees are receiving more than the minimum wage in region $1 .{ }^{15}$ This finding also means that employees can provide their basic needs and more. In terms of the department the employees are assigned it can be seen that nurses still dominates the workforce of the hospital, this is supported by the claims of Mclaughlin and Olson that the most numbers of hospital employees are the nurses. ${ }^{16}$ Moreover, Jones said that nurses are the bloodline of a hospital ${ }^{17}$ and Keagy and Thomas, said that if there is no nurse, a hospital cannot operate well. ${ }^{18}$

Regarding the stress level of the employees, the mean score means that hospital employees are experiencing slight stress. Low level of stress according to experts at the University of Bristol and the Karolinska Institute in Sweden as cited in the Daily Mail, can lead to physical

Table 4: The relationship between the stresslevel and job performance level of the respondents $\mathrm{N}=295$

\begin{tabular}{lll}
\hline & Pearson correlation & Stress level \\
\cline { 2 - 3 } Job performance & Sig. (2-tailed) & $0.17^{* *}$ \\
\hline${ }^{* *}$ Correlation is significant at the 0.01 level (2-tailed).
\end{tabular}


and mental problems. ${ }^{19}$ Moreover, the constant exposure to mild stress has been found out to increase the risk of developing physical disability by $70 \%$ and developing a psychiatric condition doubles.

In terms of their job performance, employees have an excellent rating for their job. A high-performance organization provides a competitive advantage. ${ }^{20,21}$ This finding is good for the hospital; since it is a privately owned having a high-performing human resource is good for the business side of the hospital.

This result in Pearson-r means that as the stress level goes up, the employees are poorly performing. This finding confirms the claim of "The Inverted-U Theory" that as stress goes high work performance is decreasing. The finding is parallel to the study of Alkubaisi, that stress has a negative impact on employees work performance. $^{22}$

\section{CONCLUSION}

In light with the following findings, the researchers conclude that: the hospital employees in a secondary hospital in Urdaneta City are young adults, that is female dominated and are relative neophytes who are making a decent amount of money, who are nurses. Hospital employees are experiencing minimal stress. The employees are a high-performing human resource. The stress level of the employees has a minimal damaging connection with their overall job performance.

\section{Recommendations}

Based on the results and conclusion of this study the following recommendations are drawn:

The hospital administrators may think of ways to lessen the turnover rate of the hospital so that the hospital will retain the quality of human resource.

The hospital human resource department should have a wellness program that addresses the stress that is being experienced by the employees.

The hospital human resource department and other department heads should continue the performance evaluation that they are conducting so that they can monitor the progress of the job performance of the employees, the data from the evaluation could also be a basis for the enhancement or modification of the proposed plan that was formulated out from this study.

The hospital human resource department is encouraged to execute the proposed plan that was formulated out of this study, so that employees will have high job satisfaction, effective stress management of the employees, and to promote the overall wellness of the employees, thus, enhancing their productivity.
For future researchers, it is encouraged to replicate the same study with a broader scope that includes the government hospitals, and hospitals that are classified as primary and tertiary hospitals. It is also encouraged to conduct a study that will test the different stress levels experienced by hospital employees since that is one of the limitations of this study. Moreover, it is also recommended that a study to seek the major sources and causes of the stress of hospital employees should be explored.

\section{CLINICAL SIGNIFICANCE}

The results of this study will be a guide for the plans and activities in stress control, and enhancement of employees' job performance. Moreover, the results of this study will increase the employees' awareness about the stress they are experiencing, their job performance level, and how stress influences their job performance. The findings of this study will also give patients information about the quality of service the employees provide to them.

\section{REFERENCES}

1. Stoppler, M. Stress [Internet]. 2018. Available from https:// www.medicinenet. com/stress/article.htm\#stress_facts.

2. The American Institute of Stress. What is Stress? [Internet]. n.d. Available from https://www.stress.org/what-is-stress/

3. Tan, M. Stress and the Filipino [Internet]. 2006. Available from http://pcij.org/stories/stress-and-the-filipino/.

4. Hamlett, C. How Stress Affects Your Work Performance [Internet]. 2018. Available from https://smallbusiness.chron. com/stressaffects-work-performance-18040.html.

5. McGurgen, H. Overall Effects of Organizational Stress [Internet]. n.d. Available from http://smallbusiness.chron. com/overall-effectsorganizational-stress-32322.html.

6. The Wharton School, University of Pennsylvania. Job Performance [Internet]. 2011. Available from http://kwhs. wharton.upenn.edu/term/job-performance/.

7. Hordos, L. What is the Definition of Job Performance? [Internet]. 2018. Available from https://bizfluent.com/info7856570-definition-jobperformance.html.

8. Ankari, G. Relationship Between Stress and Job Performance [Internet]. 2011. Available from http://kalyan-city.blogspot. com/2011/03/relationship-between-stress-and-job.html.

9. Sincero, M. How does Stress Affect Performance? [Internet]. 2012. Available from https://explorable.com/how-does-stressaffect-performance.

10. Polit, D. and Beck, C. Essentials of Nursing Research Ninth Edition. USA :Lippincott Williams \& Wilkins; 2017.

11. Laerd Dissertation. Total Population Sampling [nternet]. 2012. Available from http://dissertation.laerd.com/totalpopulation-sampling.php.

12. Khalili, R., Sirati, M., Ebadi, A. Tavallai, A., and Habibi, M. Validity and reliability of the Cohen 10-item Perceived Stress Scale in patients with a chronic headache: Persian version. Asian Jornal of Psychiatry. 2017 April; 26:136-140.

13. Philippine Statistics Authority. Statistical Tables on Labor Force Survey (LFS) [Inernet]. 2017. Available from https://www.psa.gov. ph/content/statistical-tables-laborforce-survey-lfs-october-2017. 
14. Rigby, R. Have you been working for the same company for too long? [Internet] 2017. Available from https://www.telegraph. co.uk/men/thinking-man/have-working-company-long/

15. National Wages and Productivity Commission. Salary Per Region; 2018. Available from http://www.nwpc.dole.gov.ph/

16. Mclaughlin, D. and Olson, J. Healthcare Operations Management Third Edition. USA: Health Administration Press; 2017.

17. Jones, R. Nursing Leadership and Management: Theories, Process, and Practice. USA: Davis Company; 2007.

18. Keagy, B. and Thomas, M. Essentials of Physician Practice Management. USA: Jossey-Bass; 2004.

19. Daily Mail. Why even mild stress can affect performanceat work [Internet]. 2011. Available from https://www.dailymail.co.uk/
health/article-1369426/Mild-stress-affect-performance-work. html.

20. Hogg, B. The Importance of a Distinctive, High-Performance Culture [Internet]. 2018. Available from https://www.billhogg.ca/the-importance-of-a-distinctive-high-performanceculture/.

21. Cornett, I. Why High-Performance Culture Is More Important Than You Think [Internet]. 2017. Available from https:// www.eaglesflight.com/blog/why-high-performance-cultureis-more-important-than-you-think.

22. Alkubaisi MM. How can stress affect your work performance? Quantitative field study on Qatari banking sector. Business and Management Research. 2015 Mar;4(1):99. 